\title{
Vaginal Misoprostol for Cervical Priming Before Outpatient Hysteroscopy: A Randomized Controlled Trial
}

\author{
Mohamed Ibrahim Amer, and Malames Faisal, Anis Mansour Nagib Younis \\ Department of Obstetrics and Gynecology, Faculty of Medicine, Ain shams University, Cairo, Egypt \\ Corresponding author: Anis M.N Younis, Mobile: 01128181509; Email: niso0200@gmail.com
}

\begin{abstract}
Background: Misoprostol has generally shown good efficacy in promoting cervical softness and facilitating hysteroscopic procedures.

Objective: To evaluate the efficacy and safety of vaginal misoprostol for cervical priming before diagnostic outpatient hysteroscopy $(\mathrm{OH})$ without anesthesia.

Patients and Methods: Design: Double-blind randomized controlled trial. Setting: University teaching hospital. Patient(s): Ninety patients requiring diagnostic $\mathrm{OH}$ for investigation of infertility or abnormal uterine bleeding in the reproductive age. Intervention(s): Patients were randomly allocated into two equal groups ( $\mathrm{n}=$ 45). In group I, $200 \mathrm{mcg}$ misoprostol was inserted into the posterior vaginal fornix 3 hours before $\mathrm{OH}$; in group II (control), $250 \mathrm{mg}$ metronidazole as placebo was inserted into the posterior vaginal fornix by investigator. A rigid 30 4-mm hysteroscope was used in the vaginoscopic technique. Main Outcome Measure(s): Ease of cervical entry (Likert scale), procedural time, patient acceptability (Likert scale), and pain scoring (visual analog scale).

Result(s): Vaginal misoprostol significantly facilitated the procedure; cervical entry was easier, procedural time was shorter, patient acceptability was higher, and pain scoring was lower in group I compared with group II. Side effects of misoprostol were infrequent, minor, and transient. No complications were reported.

Conclusion(s): The regimen of $200 \mathrm{mcg}$ vaginal misoprostol administered 3 hours before diagnostic $\mathrm{OH}$ is a simple, effective, and safe method of cervical priming to facilitate the procedure without anesthesia.
\end{abstract}

Keywords: Misoprostol, cervical priming, outpatient hysteroscopy

\section{INTRODUCTION}

Hysteroscopy is considered the "gold standard" for diagnosing intrauterine pathology. With the invention of the miniature hysteroscope, it is possible to perform hysteroscopy in an office setting (outpatient hysteroscopy $[\mathrm{OH}]$ ) without anesthesia for diagnostic indications and certain operative procedures (1). However, the experience of pain related to the procedure can be a major limitation for $\mathrm{OH}$ as a standard of care. This is often caused by the diameter of the hysteroscope and/or cervical resistance ${ }^{(2)}$.

Several alternatives have been proposed to perform the procedure with an acceptable patient compliance. Local anesthetic reduces the pain experienced by women during $\mathrm{OH}$. This occurs with paracervical and intracervical injections of anesthetic but not with transcervical and topical application; paracervical injection seems to be the most effective method of administering local anesthetic for the procedure. Nevertheless, the injection of paracervical anesthetic may cause pain and bleeding ${ }^{(3)}$.

Although hysteroscopy has been considered as a safe and less invasive procedure, some complications such as cervical tear, bleeding, uterine perforation, pain and discomfort may occur during the process ${ }^{(4)}$. Many women need dilatation prior to hysteroscopy to make the procedure simpler.
Traditional methods of cervical dilatation pre-procedure include the use of hegar's dilators or luminaria tents, which could cause significant patient discomfort, and at the same time potentially induce bleeding and hamper views obtained at hysteroscopy. The efficacy of misoprostol as a cervical ripening agent in the pregnant uterus is well established. However, there are varying reports regarding efficacy and incidence of side effects when misoprostol is used prior to hysteroscopy ${ }^{(5)}$.

Misoprostol (prostaglandin E1 analog) is a drug of choice for cervical ripening, labor induction, post-partum hemorrhage and pregnancy termination ${ }^{(6)}$.

There is evidence supporting the use of misoprostol as a cervical priming agent before some gynecologic procedures, such as intrauterine device insertion and hysteroscopy ${ }^{(7)}$.

The most common side effects with use of misoprostol in non-pregnant women are mild abdominal cramps, vaginal bleeding, febrile episodes, nausea and diarrhea ${ }^{(8)}$.

This study aims at evaluation the efficacy and safety of vaginal misoprostol for cervical priming to facilitate the procedure of diagnostic $\mathrm{OH}$ without the use of anesthesia, in patients with infertility or abnormal uterine bleeding (AUB). 


\section{PATIENTS AND METHODS}

This double-blind randomized controlled trial was conducted at the $\mathrm{OH}$ Clinic of the Department of Obstetrics and Gynecology, Faculty of Medicine, Ain Shams University, from April 2017 to October 2017. The study population consisted of 90 patients requiring diagnostic $\mathrm{OH}$ for investigation of infertility or AUB in the reproductive age. The study protocol was approved by the Scientific Research Committee of the department, and informed consent was obtained from each of the patient, the present study was conducted as a randomized, double-blind, placebo-controlled trial.

The women were allocated into two groups with a ratio of $1: 1$ by using computer-generated random numbers: group I (misoprostol group) and group II (control group). The patients were blinded to group allocation. All patients underwent vaginal examination 3 hours before $\mathrm{OH}$. In group I (the misoprostol group) included 45 women who received one tablet of $200 \mathrm{mcg}$ misoprostol (Misotac; Sigma Pharm) vaginally. Group II (the control group) also comprised 45 women who received one tablet of $250 \mathrm{mg}$ metronidazole as placebo vaginally.

Our exclusion criteria included: 1) contraindications to $\mathrm{OH}$ (i.e., pregnancy, cervical malignancy, pelvic inflammatory disease, etc.) 2) contraindications to prostaglandins (i.e., cardiovascular disease, hypertension, renal failure, etc.) 3) Previous cesarean delivery; 4) previous cervical surgery; and 5) neurologic disorders affecting the evaluation of pain.

Details of medical, obstetric, and gynecological history were obtained by subjecting all participants to a physical examination; data on their personal history were also obtained.

The misoprostol group received one tablet of $200 \mathrm{mcg}$ misoprostol, whereas the control group received one tablet of $250 \mathrm{mg}$ metronidazole as placebo vaginally ${ }^{(9)}$.

The placebo tablets were identical to misoprostol in appearance and dosing schedule. We used metronidazole tablets as placebo because it is absorbed through the vaginal epithelium, has no effect on cervical tissue or the uterine musculature, and also has no significant systemic effects ${ }^{(9)}$.

Randomization was carried out using closed opaque envelopes containing a paper in which the type of intervention to be carried out was mentioned. The sealed envelopes were opened just before administering the drugs, which were inserted deep into the posterior fornix of the vagina without revealing the type of tablet to the patients. The tablets were inserted $3 \mathrm{~h}$ before outpatient hysteroscopy.

All patients underwent postmenstrual $\mathrm{OH}$ between days 7 and 11 of the cycle (except in patients with irregular bleeding). The operator performing the procedure was blinded to group allocation. A rigid $304-\mathrm{mm}$ hysteroscope (Karl Storz Endoscopy) was used without anesthesia or analgesia. The uterine cavity was distended with normal saline solution at a pressure of $100-120 \mathrm{~mm}$ $\mathrm{Hg}$. The vaginoscopic "no touch" technique was followed; no speculum or tenaculum was used.

The main outcome measures included: 1) ease of entry of the $\mathrm{OH}$ into the cervix recorded on a 5-point Likert scale ${ }^{(7)}$ : very difficult $=1$, difficult $=2$, fair $=3$, easy $=4$, and very easy $=5$;

2) procedural time from introduction of the $\mathrm{OH}$ through the external cervical os and the visualization of the uterine cavity; 3) patient acceptability recorded by the patient on a 5-point Likert scale; 4) pain scoring recorded by the patient on a 10 -point visual analog scale (VAS) ${ }^{(8)}$; 5) side effects of misoprostol.

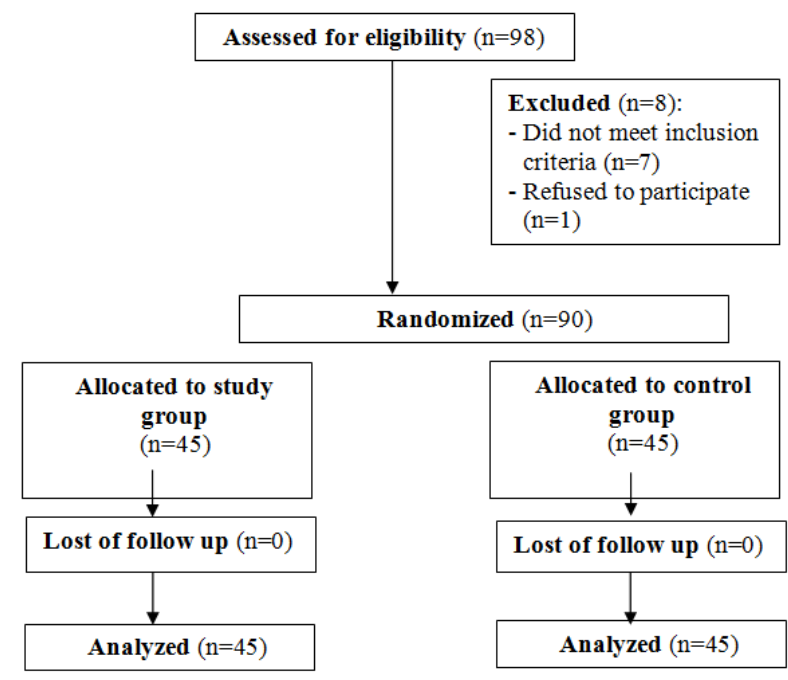

Figure (1): CONSORT, Patient flow chart.

\section{Statistical Analysis}

The collected data were coded, tabulated, and statistically analyzed using IBM SPSS statistics (Statistical Package for Social Sciences) software version 22.0, IBM Corp., Chicago, USA, 2013. 
Descriptive statistics were done for quantitative data as minimum\& maximum of the range as well as mean \pm SD (standard deviation) for quantitative normally distributed data, while it was done for qualitative data as number and percentage.

Inferential analyses were done for quantitative variables using independent t-test in cases of two independent groups with normally distributed data. In qualitative data, inferential analyses for independent variables were done using Chi square test for differences between proportions and Fisher's exact test for variables with small expected numbers. The level of significance was taken at $\mathrm{P}$ value $<0.050$ is significant, otherwise is non-significant.

\section{RESULTS}

The study population consisted of 90 patients allocated into two groups: group I (misoprostol group; 45 patients) and group II (control group; 45 patients). There was no statistically significant difference in the clinical characteristics (age, gravidity, parity, and nulliparous rate) between the two groups. The indications of hysteroscopy (primary infertility, secondary infertility, and AUB) were also not significantly different (Table 1).

The use of vaginal misoprostol significantly facilitated the procedure of $\mathrm{OH}$. Cervical entry (Likert scale) was easier in group I $(4.2 \pm 0.9)$ than in group II $(3.1 \pm 1.1): \quad \mathrm{P}<0.001$ (Table 2). Procedural time (minutes) from introduction of the $\mathrm{OH}$ through the external cervical os and the visualization of the uterine cavity was shorter in group I (2.2 \pm 0.5$)$ than in group II (2.8 \pm 0.5$)$ : $\mathrm{P}<0.001$ (Table 3). Patient acceptability (Likert scale) was higher in group I (3.2 \pm 0.8$)$ than in group II $(2.1 \pm 0.9)$ : $\mathrm{p}<0.001$ (Table 4). Pain scoring (VAS) was lower in group I $(3.4 \pm 1.2)$ than in group II $(5.3 \pm 1.3): \mathrm{P}<0.001$ (Table 5).

Side effects of misoprostol were minor and transient; nausea was reported in six patients (13.3\%), vomiting in two patients (4.4\%), abdominal pain in five patients $(11.1 \%)$, diarrhea in four patients (8.9\%), fever in two patients $(4.4 \%)$ and shivering in one patient $(2.2 \%)$. These side effects were also not significantly higher than in the control group (Table 6). There were no cases of vaginal bleeding or spotting related to misoprostol use. No complications were reported from the use of $\mathrm{OH}$ in our series.
Table (1): Demographic characteristics among the studied groups.

\begin{tabular}{|l|l|c|c|c|}
\hline \multicolumn{1}{|c|}{ Variables } & Measures & $\begin{array}{c}\text { Study } \\
(\mathbf{N}=\mathbf{4 5})\end{array}$ & $\begin{array}{c}\text { Control } \\
\mathbf{( N = 4 5 )}\end{array}$ & $\mathbf{P}$ \\
\hline Age & Mean \pm SD & $31.3 \pm 4.0$ & $32.4 \pm 3.9$ & $0.198^{*}$ \\
(years) & Range & $24.0-39.0$ & $23.0-40.0$ & \\
\hline BMI & Mean \pm SD & $27.5 \pm 1.1$ & $27.9 \pm 1.4$ & $0.250^{*}$ \\
$(\mathrm{~kg} / \mathrm{m} 2)$ & Range & $23.7-29.7$ & $25.1-31.3$ & \\
\hline Parity & Nulli & $22(48.9 \%)$ & $19(42.2 \%)$ & $\#$ \\
$(\mathrm{n}, \%)$ & Multi & $23(51.1 \%)$ & $26(57.8 \%)$ & 0.525 \\
\hline Indications & Infertility & $38(84.4 \%)$ & $35(77.8 \%)$ & $\#$ \\
(n, \%) & AUB & $7(15.6 \%)$ & $10(22.2 \%)$ & 0.419 \\
\hline
\end{tabular}

*Independent t-test, \#Chi square test

No significant differences between the studied groups regarding demographic characteristics.

Table (2): Ease of cervical entry (/5) among the studied groups.

\begin{tabular}{|l|c|c|c|}
\hline \multicolumn{1}{|c|}{ Measures } & $\begin{array}{c}\text { Misoprostol } \\
(\mathbf{N}=45)\end{array}$ & $\begin{array}{c}\text { Control } \\
(\mathbf{N}=\mathbf{4 5})\end{array}$ & \multirow{2}{*}{${ }^{*}$} \\
\hline Mean \pm SD & $4.2 \pm 0.9$ & $3.1 \pm 1.1$ & \multirow{2}{*}{$<0.001 \#$} \\
\hline Range & $2.0-5.0$ & $1.0-5.0$ & \\
\hline \multicolumn{3}{|c|}{ Impact of misoprostol over placebo } \\
\hline Items & Mean \pm SE & $95 \%$ CI \\
\hline Velocity increase & $1.1 \pm 0.2$ & $0.6-1.5$ \\
\hline
\end{tabular}

*Independent t-test, Paired t-test, \#significant, CI: Confidence interval

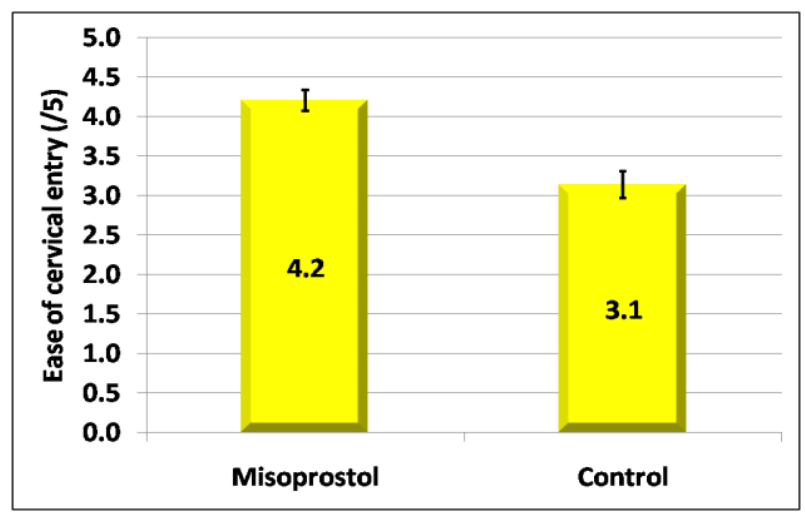

Figure (2): Ease of cervical entry between studied groups.

Table (2) and figure (2) show that: Ease of cervical entry was significantly higher among misoprostol group than among control group.

Table (3): Procedural time (minutes) among the studied groups.

\begin{tabular}{|l|c|c|c|}
\hline \multicolumn{1}{|c|}{ Measures } & $\begin{array}{c}\text { Misoprostol } \\
(\mathbf{N}=\mathbf{4 5})\end{array}$ & $\begin{array}{c}\text { Control } \\
(\mathbf{N}=\mathbf{4 5})\end{array}$ & \multirow{2}{*}{${ }^{*}$} \\
\hline Mean \pm SD & $2.2 \pm 0.5$ & $2.8 \pm 0.5$ & \multirow{2}{*}{$<0.001 \#$} \\
\hline Range & $1.2-3.4$ & $1.8-4.3$ \\
\hline \multicolumn{3}{|c|}{ Impact of misoprostol over placebo } \\
\hline Time reduction & Mean \pm SE & $95 \%$ CI \\
\hline *Independent t-test, Paired t-test, \#Significant, CI:
\end{tabular}

Confidence interval 


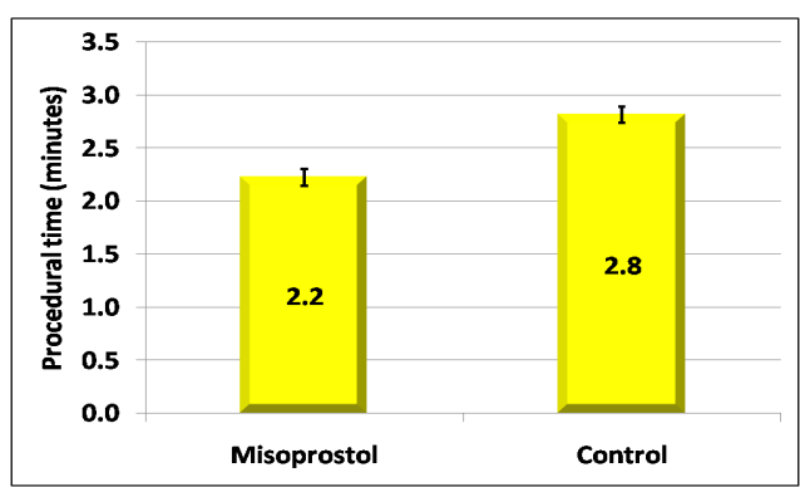

Figure (3): Procedural time among the studied groups.

Table (3) and figure (3) show that: Procedural time was significantly lower among misoprostol group than among control group.

Table (4): Pain (/10) among the studied groups.

\begin{tabular}{|l|c|c|c|}
\hline \multicolumn{1}{|c|}{ Measures } & $\begin{array}{c}\text { Misoprostol } \\
(\mathbf{N}=\mathbf{4 5})\end{array}$ & $\begin{array}{c}\text { Control } \\
(\mathbf{N}=\mathbf{4 5})\end{array}$ & \multirow{2}{*}{${ }^{*}$} \\
\hline Mean \pm SD & $3.4 \pm 1.2$ & $5.3 \pm 1.3$ & \multirow{2}{*}{$<0.001 \#$} \\
\hline Range & $1.0-6.0$ & $2.0-7.0$ & \\
\hline \multicolumn{3}{|c|}{ Impact of misoprostol over placebo } \\
\cline { 1 - 3 } Items & Mean \pm SE & $95 \%$ CI \\
\hline Velocity increase & $1.9 \pm 0.3$ & $1.4-2.4$ \\
\hline
\end{tabular}

*Independent t-test, Paired t-test, \#Significant, CI: Confidence interval

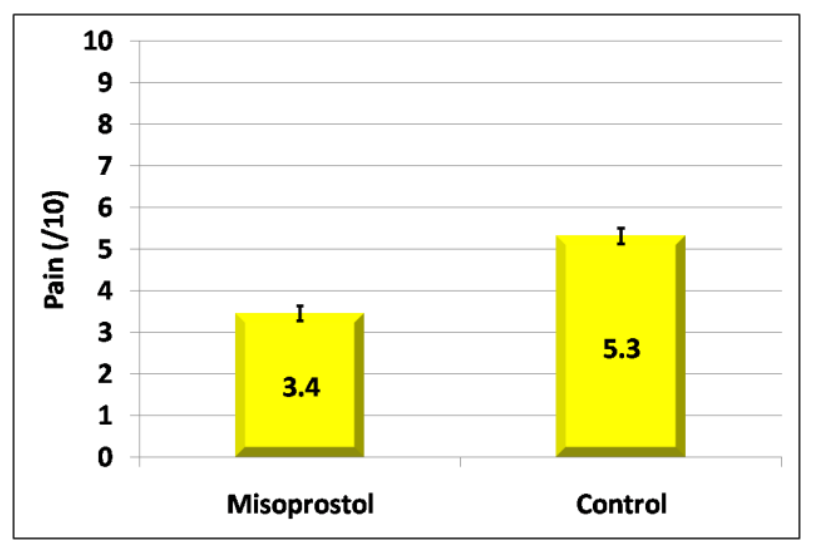

Figure (4): Pain among the studied groups.

Table (4) and figure (4) show that: Pain was significantly lower among misoprostol group than among control group.

Table (5): Patient acceptability (/5) among the studied groups.

\begin{tabular}{|c|c|c|c|}
\hline Measures & $\begin{array}{c}\text { Misoprosto } \\
(\mathrm{N}=45)\end{array}$ & $\begin{array}{l}\text { Contro } \\
(\mathrm{N}=45)\end{array}$ & P* \\
\hline Mean \pm SD & $3.2 \pm 0.8$ & $2.1 \pm 0.9$ & \multirow{2}{*}{$<0.001 \#$} \\
\hline Range & $2.0-4.0$ & $1.0-4.0$ & \\
\hline \multicolumn{4}{|c|}{ Impact of misoprostol over placebo } \\
\hline \multicolumn{2}{|c|}{ Items } & Mean \pm SE & $95 \% \mathrm{CI}$ \\
\hline \multicolumn{2}{|c|}{ Velocity increase } & $1.2 \pm 0.2$ & $0.8-1.5$ \\
\hline
\end{tabular}

*Independent t-test, Paired t-test, \#Significant, CI: Confidence interval

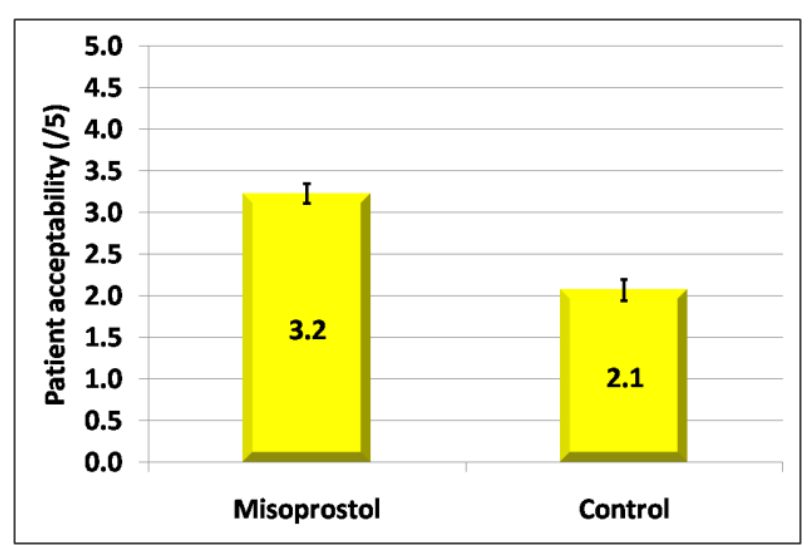

Figure (5): Patient acceptability among the studied groups.

Table (5) and figure (5) show that: Patient acceptability was significantly higher among misoprostol group than among control group.

Table (6): Side effects among the studied groups.

\begin{tabular}{|l|c|c|c|c|}
\hline \multicolumn{1}{|c|}{ Side effects } & $\begin{array}{c}\text { Misoprostol } \\
(\mathbf{N = 4 5})\end{array}$ & $\begin{array}{c}\text { Control } \\
(\mathbf{N = 4 5})\end{array}$ & $\# \mathbf{P}$ & $\begin{array}{c}\text { RR } \\
\mathbf{9 5 \%} \mathbf{C I})\end{array}$ \\
\hline Nausea & $6(13.3 \%)$ & $1(2.2 \%)$ & 0.110 & $\begin{array}{c}1.82 \\
(1.25-2.66)\end{array}$ \\
\hline Vomiting & $2(4.4 \%)$ & $0(0.0 \%)$ & 0.494 & -- \\
\hline Abdominal pain & $5(11.1 \%)$ & $2(4.4 \%)$ & 0.434 & $\begin{array}{c}1.48 \\
(0.88-2.49)\end{array}$ \\
\hline Diarrhea & $4(8.9 \%)$ & $0(0.0 \%)$ & 0.117 & -- \\
\hline Fever & $2(4.4 \%)$ & $0(0.0 \%)$ & 0.494 & -- \\
\hline Shivering & $1(2.2 \%)$ & $0(0.0 \%)$ & 1.000 & -- \\
\hline
\end{tabular}

\#Fisher's exact test, RR: Relative risk, CI: Confidence interval

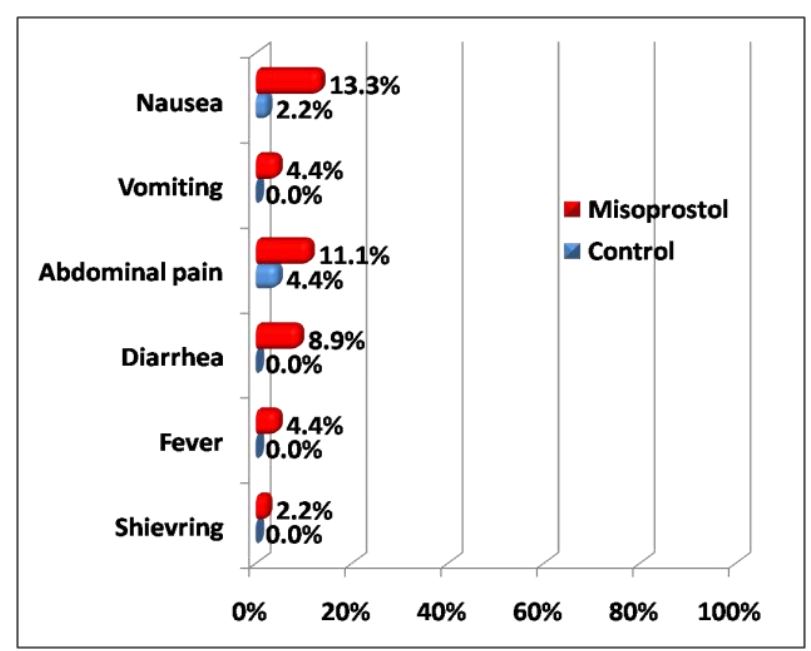

Figure (6): Side effects among the studied groups.

Table (6) and figure (6) show that: Different side effects were non-significantly more frequent among misoprostol group than among control group. No complications reported from the use of $\mathrm{OH}$. 


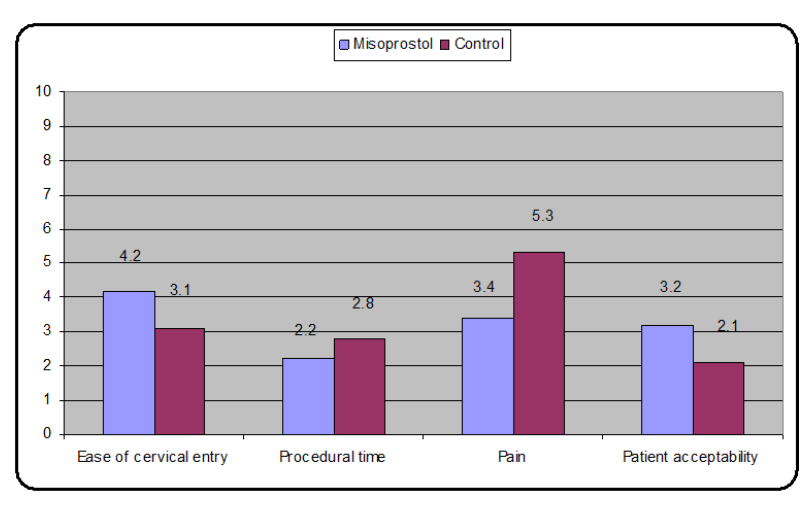

Figure (7): Outcome measurement.

\section{DISCUSSION}

Hysteroscopy is a well-established, gold standard diagnostic imaging tool in modern gynecology ${ }^{(10)}$. It is globally used for the evaluation of conditions affecting the uterine cavity, for example, bleeding disorders and infertility. In the last two decades, technology has advanced further towards miniaturization, leading to the introduction of mini-hysteroscopes with a maximal diameter of $5 \mathrm{~mm}$ and less. Therefore, hysteroscopy has become a suitable outpatient or surgery procedure without the need for anesthesia or theatre access. Outpatient hysteroscopy, even when performed under these restrictions, has proven to be a safe, cost-effective procedure that is well tolerated by women ${ }^{(11)}$.

In the present study, we evaluated the efficacy and safety of vaginal misoprostol for cervical priming at a dose of $200 \mathrm{mcg} 3$ hours before diagnostic $\mathrm{OH}$ without anesthesia in patients with infertility or AUB. There was an overlap of patient samples with infertility in this study and our previous study about the value of $\mathrm{OH}$ as a routine investigation of uterine factor of infertility before assisted reproductive techniques.

Our results indicate that the use of vaginal misoprostol significantly facilitated the procedure of $\mathrm{OH}$ : Cervical entry was easier, procedural time was shorter, patient acceptability was higher, and pain scoring was lower in the misoprostol group compared with the control group. Misoprostol-related side effects (nausea, vomiting, abdominal pain, diarrhea, fever, and shivering) were infrequent, minor, and transient, and no complications were reported. Increasing the dose of vaginal misoprostol to $>400$ mcg or increasing the interval beyond 3 hours has not improved the effect on cervical dilatation, but it has increased side effects, mainly diarrhea and shivering (12).
Misoprostol is potentially effective for cervical dilatation before hysteroscopy ${ }^{(13)}$. The route of misoprostol administration for cervical dilatation can be oral, vaginal, or sublingual. Among the three routes, vaginal administration has higher bioavailability ${ }^{(14)}$ less severe gastrointestinal side effects, and longer sustained effect ${ }^{(15)}$. Batukan et al. found that vaginal administration was more effective than the oral route for preoperative cervical ripening (16) while other studies found no difference between the two routes or among the three routes ${ }^{(17)}$.

In agreement with our results, SordiaHernandez et al. ${ }^{(\mathbf{1 8})}$ reported that vaginal misoprostol at a dose of $200 \mathrm{mcg}$ inserted 12 hours apart, starting 24 hours before $\mathrm{OH}$ without anesthesia for investigation of infertility, considerably reduces pain and the time needed for hysteroscopy compared with oral misoprostol administration and placebo. They reported only one patient with nausea and two patients with referred abdominal pain in the vaginal misoprostol group $(\mathrm{n}=20)$.

Darwish et al. ${ }^{(19)}$ reported that $200 \mathrm{mcg}$ intravaginal misoprostol and endocervical laminaria were equally effective in inducing proper cervical priming before operative hysteroscopy in patients with diagnosed intrauterine lesions. Nevertheless, they observed that misoprostol may be superior, owing to easy application, reduced cost, and patient convenience and acceptability.

Da Costa et al. ${ }^{(20)}$ also found that $200 \mathrm{mcg}$ of vaginal misoprostol reduced pain severity during diagnostic hysteroscopy in postmenopausal women. However, Oppegaard et al. ${ }^{\text {(21) }}$ concluded that 1,000 mcg vaginal misoprostol 12 hours before operative hysteroscopy has a significant cervical ripening effect compared with placebo in premenopausal but not postmenopausal women. In contrast to our results, Fernandez et al. ${ }^{(22)}$ found that vaginal misoprostol applied 4 hours before operative hysteroscopy in premenopausal women, at three different doses (200, 400 , or $800 \mathrm{mcg}$ ), did not reduce the need for cervical dilatation, did not facilitate hysteroscopic surgery, and increased preoperative pain.

Valente et al. ${ }^{(23)}$ also observed that with the dose used in their study (400 mcg); vaginal misoprostol induced vaginal bleeding and precluded diagnostic anesthesia-free hysteroscopy in patients of reproductive age. Singh et al. ${ }^{(24)}$ found that $400 \mathrm{mcg}$ vaginal misoprostol 4-6 hours before diagnostic hysteroscopy did not facilitate 
cervical dilation. Although it did effect a reduction in pain scores, there was no difference in patient satisfaction, need for analgesia, or sedation.

It should be pointed out that all the misoprostol side effects such as diarrhea, fever, nausea, mild abdominal pain, and bleeding are significantly increased after the use of misoprostol. However, these side effects are generally minor, transient, and well tolerated by patients. Misoprostol side effects are related to dosage, interval, and route of administration. Increasing the dose and interval of vaginal misoprostol does not improve the effect on cervical dilatation but does increase the side effects. In addition, misoprostol, when administered vaginally, has fewer side effects compared with oral or sublingual administration ${ }^{(25)}$.

In conclusion, our results indicate that the use of vaginal misoprostol as a cervical priming agent is a simple method to facilitate the procedure of diagnostic $\mathrm{OH}$ without anesthesia in patients with infertility or AUB. Reduction of misoprostol dosage $(200 \mathrm{mcg})$ with shortening of the time interval between misoprostol administration and the procedure ( 3 hours) has been proven to be an effective regimen with minimal side effects.

\section{REFERENCES}

1. Bettocchi S, Ceci O, Nappi L, di Venere R, Masciopinto V, and Pansini V (2004): Operative office hysteroscopy without anesthesia: analysis of 4863 cases performed with mechanical instruments. J Am Assoc Gynecol Laparosc., 11:59-61.

2. Campo R, Molinas CR, Rombauts $\mathrm{L}$, Mestdagh G, Lauwers M, and Braekmans P (2005): Prospective multicentre randomized controlled trial to evaluate factors influencing the success rate of office diagnostic hysteroscopy. Hum Reprod., 20:258-63.

3. Vercellini P, Colombo A, Munro F, Oldani S, Bramante T, Crosignani PG (1995): Paracervical anesthesia for outpatient hysteroscopy. Fertil Steril., 64:221-2.

4. Jansen FW, Vredevoogd CB, van Ulzen $K$, Hermans J, Trimbos JB, Trimbos-Kemper TC (2000): Complications of hysteroscopy: a prospective, multicenter study. Obstet Gynecol., 96:266-270.
5. Preen AE, Mc-Keeby JL, Catherino W, Alvero RJ (2002): Oral misoprostol prior to operative hysteroscopy does not enhance cervical dilation or improve operative time: a prospective randomized, double blind, placebocontrolled trial. Fertil Steril., 78(3):S79-S80.

6. Goldberg AB, Greenberg MB, Darney PD (2001): Misoprostol and pregnancy. N Engl J Med., 344:38-47.

7. Crane JM, Healey S (2006): Use of misoprostol before hysteroscopy: a systematic review. J Obstet Gynaecol Can.,28:373-9.

8. Preutthipan S, Herabutya Y (2006): A randomized comparison of vaginal misoprostol and dinoprostone for cervical priming in nulliparous women before operative hysteroscopy. Fertil Steril., 86:990-994.

9. Saha PS, Bhattacharjee N, Baru G (2007): Vaginal misoprostol for cervical priming before gynecological procedure on nonpregnant women. Int J Health Sci., 1:185-193.

10. Preutthipan S, Linasmita V (2003): A prospective comparative study between hysterosalpingography and hysteroscopy in the detection of intrauterine pathology in patients with infertility. J Obstet Gynaecol Res., 29: 33-37.

11. Van Dongen $H$, Kroon CD, Jacobi CE, Trimbos JB, Jansen FW (2007): Diagnostic hysteroscopy in abnormal uterine bleeding: A systematic review and meta-analysis. BJOG., 114: 664-675.

12. Singh K, Fong YF, Prasad RN, Dong F (1998): Randomizedtrial to determine optimal dose of vaginal misoprostol for preabortion cervical priming. Obstet Gynecol., 92:795-8.

13. Crane JM, Healey S (2006): Use of misoprostol before hysteroscopy: a systematic review. J Obstet Gynaecol Can., 28 (5): 373379.

14. Tang OS, Gemzell-Danielsson K, Ho PC (2007): Misoprostol: pharmacokinetic profiles, effects on the uterus and side-effects. Int $\mathbf{J}$ Gynaecol Obstet., 99(2):160-167.

15. Tang OS, Schweer H, Seyberth HW, Lee SW, Ho PC (2002): Pharmacokinetics of different routes of administration of misoprostol. Hum Reprod., 17(2):332-336. 
16. Batukan C, Ozgun MT, Ozcelik B, Aygen E, Sahin Y, Turkyilmaz C (2008): Cervical ripening before operative hysteroscopy in premenopausal women: a randomized, doubleblind, placebo-controlled comparison of vaginal and oral misoprostol. Fertil Steril., 89(4):966-973.

17. Lee YY, Kim TJ, Kang H et al. (2010): The use of misoprostol before hysteroscopic surgery in non-pregnant premenopausal women: a randomized comparison of sublingual, oral and vaginal administrations. Hum Reprod., 25(8):1942-1948.

18. Sordia-Hernandez LH, Rosales-Tristan E, VazquezMendez J, Merino M, Iglesias JL, Garza-Leal JG et al. (2011): Effectiveness of misoprostol for office hysteroscopy without anesthesia in infertile patients. Fertil Steril., 95:759-61.

19. Darwish AM, Ahmad AM, Mohammad AM (2004): Cervicalpriming prior to operative hysteroscopy: a randomized comparison of laminaria versus misoprostol. Hum Reprod., 19:2391-4.

20. Da Costa AR, Pinto-Neto AM, Amorim M, Paiva LH,Scavuzzi A, Schettini J (2008): Use of misoprostol prior to hysteroscopy in postmenopausal women: a randomized, placebocontrolled clinical trial. J Minim Invasive Gynecol., 15:67-73.
21. Oppegaard KS, Nesheim BI, Istre $O$, Qvigstad E (2008): Comparison of selfadministered vaginal misoprostol versus placebo for cervical ripening prior to operative hysteroscopy using a sequential trial design. BJOG., 115:663.e1-9.

22. Fernandez H, Alby JD, Tournoux C, ChauveaudLambling A, de Tayrac R, Frydman R et al. (2004): Vaginal misoprostol for cervical ripening before operative hysteroscopy in pre-menopausal women: a doubleblind, placebo-controlled trial with three dose regimens. Hum Reprod., 19:1618-21.

\section{Valente EP, de Amorim MM,} Costa AA, de Miranda DV (2008): Vaginal misoprostol prior to diagnostic hysteroscopy in patients of reproductive age: a randomized clinical trial. J Minim Invasive Gynecol., 15:452-8.

24. Singh N, Ghosh B, Naha M, Mittal S (2009): Vaginal misoprostol for cervical priming prior to diagnostic hysteroscopy efficacy, safety and patient satisfaction: a randomized controlled trial. Arch Gynecol Obstet., 279:37-40.

25. Tanha FD, Salimi S, Ghajarzadeh M (2013): Sublingual versus vaginal misoprostol for cervical ripening before hysteroscopy: a randomized clinical trial. Arch Gynecol Obstet., 287(5):937-940. 